\title{
Predictive and prognostic value of preoperative serum tumor markers in resectable adenosqamous lung carcinoma
}

\author{
Qiongjie Zhi $\mathbf{1}^{1,2,3, *}$, Yuqian Wang ${ }^{1,2,3, *}$, Xinyue Wang ${ }^{1,2,3 *}$, Dongsheng Yue ${ }^{1,2,4}$, Kai \\ Li $^{1,2,3}$ and Richeng Jiang ${ }^{1,2,3}$ \\ ${ }^{1}$ Tianjin Medical University Cancer Institute \& Hospital, National Clinical Research Center for Cancer, Tianjin, PR China \\ ${ }^{2}$ Key Laboratory of Cancer Prevention and Therapy, Tianjin, PR China \\ ${ }^{3}$ Department of Thoracic Oncology, Tianjin Lung Cancer Center, Tianjin Cancer Institute \& Hospital, Tianjin, PR China \\ ${ }^{4}$ Department of Lung Cancer, Tianjin Lung Cancer Center, Tianjin Cancer Institute \& Hospital, Tianjin Medical University, \\ Tianjin, PR China \\ * These authors have contributed equally to this work \\ Correspondence to: Richeng Jiang, email: jiangricheng@tjmuch.com
}

Kai Li, email: likai5@medmail.com.cn

Keywords: tumor marker, TMl, adenosquamous lung carcinoma, prognostic factor, EGFR mutation Received: July 18,2016 Accepted: August 26, $2016 \quad$ Published: August 30, 2016

ABSTRACT

Background: Adenosquamous carcinoma is a rare and aggressive form of lung cancer. The prognostic and predictive value of preoperative serum tumor markers and frequency of EGFR mutations in adenosquamous lung carcinoma are unclear.

Methods: We retrospectively analyzed data and samples collected from 106 radically resected adenosquamous lung carcinoma patients with pathological stage I-IIIA between 2008 and 2013. Correlations between serum tumor marker levels and EGFR mutations as well as survival parameters were analyzed and prognostic factors were identified.

Results: Of the 106 adenosquamous lung carcinoma patients, 29 (27.4\%) harbored EGFR mutations. By univariate analysis, advanced clinical stage $(P=0.009$ for disease-free survival [DFS]; $P=\mathbf{0 . 0 4 6}$ for overall survival [OS]), larger tumor size ( $P=0.001$ for DFS; $P=0.002$ for OS), regional lymph node metastasis $(P=0.024$ for DFS; $P=0.030$ for OS), higher NSE level $(P=0.002$ for DFS; $P<0.001$ for OS), and higher TMI (tumor marker index) $(P=0.009$ for $O S)$ were significantly correlated with a worse prognosis. By multivariate analysis, NSE $(P=0.014)$ was confirmed as independent predictor for DFS, while NSE $(P=0.001)$ and TMI $(P=0.038)$ were independent prognostic factors for $O S$.

Conclusion: Adenosquamous lung carcinoma is an aggressive malignancy with relatively high EGFR mutation frequency. Elevated preoperative NSE level and TMI are adverse predictive and prognostic indicators.

\section{INTRODUCTION}

Lung cancer is the leading cause of cancerrelated deaths worldwide. Non-small cell lung cancer, predominantly includes adenocarcinoma, squamous cell carcinoma and large cell carcinoma, accounts for about $80 \%$ of lung cancers. Adenosquamous lung carcinoma is a relatively rare subtype of non-small cell lung cancer comprising of $0.3 \%$ to $5 \%$ of all non-small cell lung cancers $[1,2]$.
According to criteria of World Health Organization, adenosquamous lung carcinoma is a carcinoma displaying components of both squamous cell carcinoma and adenocarcinoma, with each component comprising at least $10 \%$ of the tumor [3]. Adenosquamous lung carcinoma is regarded as more aggressive and carries a worse prognosis compared to adenocarcinoma and squamous cell carcinoma [1, 4]. However, its biological behaviors based on clinicopathological factors are not well understood. Most adenosquamous lung carcinoma patients eventually develop local recurrence and/or distant metastasis even 


\begin{tabular}{|c|c|c|}
\hline Variable & No. of Patients & $\%$ \\
\hline \multicolumn{3}{|l|}{ Age (years) } \\
\hline Median (range) & \multicolumn{2}{|l|}{$60(35-83)$} \\
\hline$<60$ & 50 & 47.2 \\
\hline$\geq 60$ & 56 & 52.8 \\
\hline \multicolumn{3}{|l|}{ Gender } \\
\hline Male & 63 & 59.4 \\
\hline Female & 43 & 40.6 \\
\hline \multicolumn{3}{|l|}{ Smoking history } \\
\hline Never & 42 & 39.6 \\
\hline Ever & 64 & 60.4 \\
\hline \multicolumn{3}{|l|}{ Component } \\
\hline Adenocarcinoma predominant & 49 & 46.3 \\
\hline Squamous cell carcinoma predominant & 26 & 24.5 \\
\hline Equal proportion & 31 & 29.2 \\
\hline \multicolumn{3}{|l|}{ Clinical stage } \\
\hline $\mathrm{I}$ & 41 & 38.7 \\
\hline $\mathrm{II}$ & 19 & 17.9 \\
\hline IIIA & 46 & 43.4 \\
\hline \multicolumn{3}{|l|}{ Tumor size } \\
\hline$\leq 3 \mathrm{~cm}$ & 36 & 44.0 \\
\hline$>3 \mathrm{~cm}$ & 70 & 56.0 \\
\hline \multicolumn{3}{|l|}{ Regional lymph node metastasis } \\
\hline No & 47 & 44.3 \\
\hline Yes & 59 & 55.7 \\
\hline \multicolumn{3}{|l|}{ Operative approaches } \\
\hline Pneumonectomy & 8 & 7.5 \\
\hline Lobectomy & 89 & 84.0 \\
\hline Wedge resection & 9 & 8.5 \\
\hline \multicolumn{3}{|l|}{ Adjuvant treatment } \\
\hline Chemotherapy & 63 & 59.5 \\
\hline Chemoradiotherapy & 10 & 9.4 \\
\hline Others/none & 33 & 31.1 \\
\hline \multicolumn{3}{|l|}{ EGFR mutation } \\
\hline Wild-type & 77 & 72.6 \\
\hline Exon 19 deletion & 13 & 12.3 \\
\hline L858R substitution & 12 & 11.3 \\
\hline Others & 4 & 3.8 \\
\hline \multicolumn{3}{|l|}{ NSE } \\
\hline$\leq 15.2 \mathrm{ng} / \mathrm{ml}$ & 68 & 64.2 \\
\hline$>15.2 \mathrm{ng} / \mathrm{ml}$ & 38 & 35.8 \\
\hline \multicolumn{3}{|l|}{ CEA } \\
\hline$\leq 5.0 \mathrm{ng} / \mathrm{ml}$ & 56 & 52.8 \\
\hline$>5.0 \mathrm{ng} / \mathrm{ml}$ & 50 & 47.2 \\
\hline \multicolumn{3}{|l|}{ Cyfra21-1 } \\
\hline$\leq 3.3 \mathrm{ng} / \mathrm{ml}$ & 48 & 45.3 \\
\hline$>3.3 \mathrm{ng} / \mathrm{ml}$ & 58 & 54.7 \\
\hline \multicolumn{3}{|l|}{ SCCA } \\
\hline$\leq 1.5 \mathrm{ng} / \mathrm{ml}$ & 90 & 84.9 \\
\hline$>1.5 \mathrm{ng} / \mathrm{ml}$ & 16 & 15.1 \\
\hline \multicolumn{3}{|l|}{ Tumor marker index (TMI) } \\
\hline$\leq 0.54$ & 17 & 16.0 \\
\hline$>0.54$ & 89 & 84.0 \\
\hline \multicolumn{3}{|l|}{ Recurrent sites $(\mathrm{n}=68)$} \\
\hline Loco-regional or lung & 23 & 33.8 \\
\hline Bone & 7 & 10.3 \\
\hline
\end{tabular}




\begin{tabular}{|l|l|l|}
\hline Brain & 11 & 16.2 \\
\hline Liver & 5 & 7.3 \\
\hline Multiple & 22 & 32.4 \\
\hline $\begin{array}{l}\text { Post-recurrence treatment } \\
\text { Systemic chemotherapy }\end{array}$ & \multicolumn{2}{|l|}{} \\
\hline No & \multicolumn{2}{|l|}{} \\
\hline Yes & 63 & 50.4 \\
\hline Radiotherapy & 43 & 40.6 \\
\hline No & \multicolumn{2}{|l|}{} \\
\hline Yes & 78 & 73.6 \\
\hline EGFR-TKI & 28 & 26.4 \\
\hline No & \multicolumn{2}{|l|}{95.3} \\
\hline Yes & 101 & 4.7 \\
\hline Total & 5 & 100 \\
\hline
\end{tabular}

after complete tumor resection, and the overall survival rates remain low. Standard platinum-based doublet chemotherapy of advanced non-small cell lung cancer has limited efficacy, thus new therapies are needed.

Recent advancements in EGFR mutation targeted therapy led to a major paradigm shift in the treatment of non-small cell lung cancer. EGFR-sensitizing mutations are strongly associated with robust responses to EGFR tyrosine kinase inhibitors (EGFR-TKI) and improved progression-free survival (PFS). However, EGFR mutations are most common in Asian patients, nonsmokers, females and those with adenocarcinoma histology [5]. In squamous cell carcinoma, the EGFR mutation rate is reported to be approximately 5\% [6]. Although several small studies have indicated that the frequency of EGFR mutation in adenosquamous lung carcinoma ranges from $15 \%$ to $44 \%$ in the East Asian population, the exact prevalence of EGFR mutation in adenosquamous lung carcinoma is still not clear.

In recent years, serum tumor markers, including neuron-specific enolase (NSE) [7-9], carcinoembryonic antigen (CEA) [10, 11], cytokeratin-19 fragments (Cyfra21-1) [12] and squamous cell carcinoma antigen (SCCA) [13] have been extensively investigated, and considered potentially predictive and prognostic in non-small cell lung cancer. However, little is known about the predictive and prognostic value of the tumor markers in patients with adenosquamous lung carcinoma. Here, we investigated the clinicopathological characteristics of adenosquamous lung carcinoma patients who underwent surgery and explored the predictive and prognostic value of serum tumor markers NSE, CEA, Cyfra21-1 and SCCA.

\section{RESULTS}

\section{Patient characteristics}

The clinical characteristics of the 106 adenosquamous lung carcinoma patients are shown in
Table 1. Sixty-three patients (59.4\%) were men and 42 (39.6\%) were never-smokers, with an age range of 35 to 83 years (median, 60 years). Among the patient histology, 49 (46.3\%) were adenocarcinoma predominant, 26 (24.5\%) squamous cell carcinoma predominant, and $31(29.2 \%)$ with equal adenocarcinoma and squamous cell carcinoma. The distribution of clinical stages was as follows: 41 stage I, 19 stage II, and 46 stage IIIA. Eight patients (7.5\%) received pneumonectomy, 89 (84.0\%) received lobectomy, and $9(8.5 \%)$ underwent wedge resection. EGFR mutations were detected in $27.4 \%(29 / 106)$ of 106 patients. Among the 29 patients with mutations, 13 harbored exon 19 deletions (del19), 13 had point mutations in exon 21 (12 were L858R, and one was L861Q), two had G719X in exon 18, and one possessed dual mutations of G719X in exon 18 and S768I in exon 20. No T790M mutations were detected in these patients.

Of the 106 adenosquamous lung carcinoma patients, $63(59.5 \%)$ were treated with platinum-based adjuvant chemotherapy, 10 (9.4\%) underwent platinum-based adjuvant chemoradiotherapy, and 68 (64.2\%) had recurrent disease during the study follow-up period. The median DFS was 15.0 months ( $95 \%$ confidence interval [CI]: 9.520.4). In addition, 43 (40.6\%) recurrent patients received systemic chemotherapy, 28 (26.4\%) patients also received radiotherapy as local therapy, and only $5(4.7 \%)$ received EGFR-TKIs. At the end of the last follow up, 69 (65.1\%) patients had died. Median overall survival was 26.0 months. The survival rates of 1,2 and 5 -year were $76.4 \%$, $52.9 \%$, and $25.3 \%$, respectively. Among the 68 patients with recurrent disease, the initially recurrent sites were the loco-regional or lung $(33.8 \%, 23 / 68)$, bone $(10.3 \%, 7 / 68)$, brain $(16.2 \%, 11 / 68)$ and liver $(7.3 \%, 5 / 68), 22(32.4 \%)$ patients had multiple recurrent sites.

\section{Association of serum tumor marker levels with clinicopathological characteristics}

As shown in Table 2, preoperative NSE, CEA, Cyfra21-1 and SCCA levels were elevated in 35.8\%, $47.2 \%, 54.7 \%$ and $15.1 \%$ of adenosquamous lung 

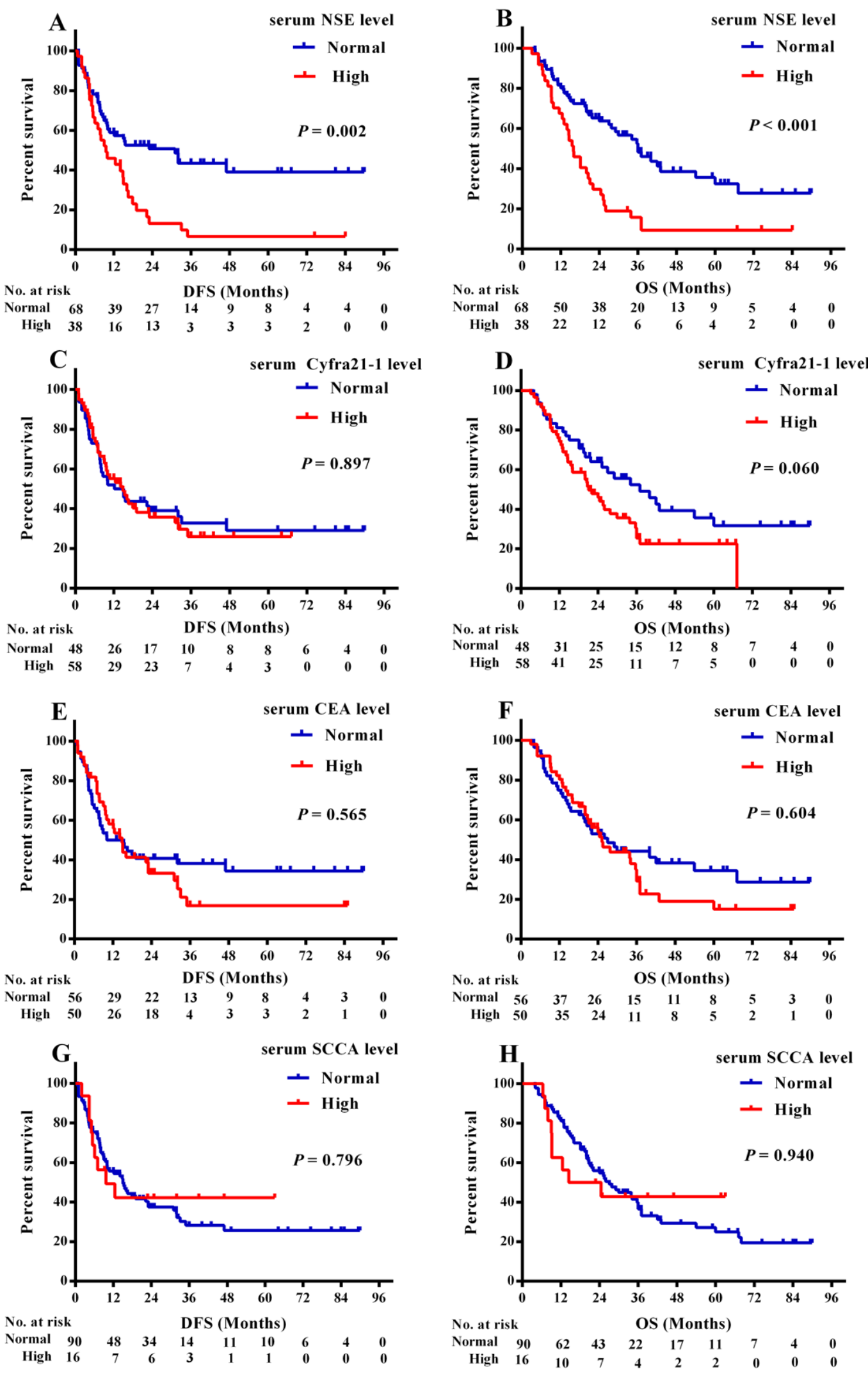

Figure 1: Kaplan-Meier survival curves of DFS and OS based on different levels of serum tumor markers. A. DFS and B. OS based on different levels of NSE; C. DFS and D. OS based on different levels of Cyfra21-1; E. DFS and F. OS based on different levels of CEA; G. DFS and H. OS based on different levels of SCCA; 


\begin{tabular}{|c|c|c|c|c|c|c|c|c|}
\hline Variable & $\begin{array}{l}\text { NSE } \\
\text { (IQR) }\end{array}$ & $\begin{array}{l}\text { CEA median } \\
\text { (IQR) }\end{array}$ & $\begin{array}{l}\text { Cyfra21-1 } \\
\text { median (IQR) }\end{array}$ & $\begin{array}{l}\text { SCCA } \\
\text { median } \\
\text { (IQR) }\end{array}$ & $\begin{array}{|lr|}\text { NSE r r } & > \\
15.2 & \mathrm{ng} / \\
\mathrm{ml}(\%) & \\
\end{array}$ & $\begin{array}{l}\text { CEA > 5.0 } \\
\text { ng/ml }(\%)\end{array}$ & $\begin{array}{l}\text { Cyfra21-1 } \\
>3.3 \mathrm{ng} / \mathrm{ml} \\
(\%) \\
\end{array}$ & $\begin{array}{l}\text { SCCA > } \\
1.5 \mathrm{ng} / \\
\mathrm{ml}(\%) \\
\end{array}$ \\
\hline \multicolumn{9}{|l|}{ Component } \\
\hline $\begin{array}{l}\text { Adenocarcinoma } \\
\text { predominant } \\
(\mathrm{n}=49)\end{array}$ & $14.2(11.6-18.3)$ & $5.5(3.0-16.1)$ & $3.8(2.4-5.1)$ & $0.8(0.4-1.3)$ & $18(36.7)$ & $26(53.0)$ & $27(55.1)$ & $7(14.3)$ \\
\hline $\begin{array}{l}\text { Squamous cell carcinoma } \\
\text { predominant }(\mathrm{n}=26)\end{array}$ & $14.7(12.8-20.6)$ & $5.7(3.2-13.9)$ & $3.5(2.5-5.3)$ & $0.8(0.5-1.0)$ & $11(42.3)$ & $15(57.7)$ & $17(65.4)$ & $3(11.5)$ \\
\hline Equal proportion $(\mathrm{n}=31)$ & $13.8(10.5-16.2)$ & $3.3(2.2-7.0)$ & $3.0(2.1-5.2)$ & $0.7(0.3-1.3)$ & $9(29.0)$ & $9(29.0)$ & $14(45.2)$ & $6(19.4)$ \\
\hline$P$-value & 0.079 & 0.169 & 0.568 & 0.987 & 0.573 & 0.052 & 0.310 & 0.735 \\
\hline \multicolumn{9}{|l|}{ Clinical stage } \\
\hline $\mathrm{I}(\mathrm{n}=41)$ & $13.5(11.4-13.5)$ & $3.6(2.2-11.6)$ & $3.2(2.1-4.6)$ & $0.8(0.3-1.2)$ & $7(17.1)$ & $16(39.0)$ & $20(48.8)$ & $3(7.3)$ \\
\hline II $(n=19)$ & $15.1(11.6-19.0)$ & $5.3(3.0-8.8)$ & $3.5(2.5-5.2)$ & $1.0(0.5-1.8)$ & $9(47.4)$ & $10(52.6)$ & $11(57.9)$ & $5(26.3)$ \\
\hline IIIA $(n=46)$ & $14.9(12.1-18.6)$ & $5.2(3.0-21.9)$ & $4.0(2.4-5.3)$ & $0.7(0.4-1.2)$ & $22(47.8)$ & $24(52.2)$ & $27(58.7)$ & $8(17.4)$ \\
\hline$P$-value & 0.016 & 0.484 & 0.422 & 0.642 & 0.006 & 0.517 & 0.620 & 0.205 \\
\hline \multicolumn{9}{|l|}{ Tumor size } \\
\hline$\leq 3 \mathrm{~cm}(\mathrm{n}=36)$ & $13.7(11.6-15.6)$ & $3.3(2.0-9.6)$ & $3.3(1.9-4.2)$ & $0.6(0.4-1.0)$ & $10(27.8)$ & $14(38.9)$ & $18(50.0)$ & $1(2.7)$ \\
\hline$>3 \mathrm{~cm}(\mathrm{n}=70)$ & $14.7(12.1-18.5)$ & $5.2(3.0-15.6)$ & $3.9(2.5-5.4)$ & $0.9(0.4-1.3)$ & $28(40.0)$ & $36(51.4)$ & $40(57.1)$ & $15(21.4)$ \\
\hline$P$-value & 0.045 & 0.448 & 0.241 & 0.207 & 0.214 & 0.221 & 0.484 & 0.011 \\
\hline \multicolumn{9}{|c|}{ Regional lymph node metastasis } \\
\hline No $(\mathrm{n}=59)$ & $13.7(11.6-15.0)$ & $3.2(2.2-12.3)$ & $3.2(2.0-5.2)$ & $0.9(0.3-1.4)$ & $28(47.5)$ & $32(54.2)$ & $35(59.3)$ & $10(16.9)$ \\
\hline Yes $(n=47)$ & $15.1(12.0-19.0)$ & $5.3(3.2-16.3)$ & $3.8(2.5-5.2)$ & $0.7(0.4-1.2)$ & $10(21.3)$ & $18(38.3)$ & $23(48.9)$ & $6(12.8)$ \\
\hline$P$-value & 0.092 & 0.197 & 0.370 & 0.534 & 0.005 & 0.102 & 0.293 & 0.550 \\
\hline \multicolumn{9}{|l|}{ EGFR mutation } \\
\hline Wild-type $(\mathrm{n}=77)$ & $14.3(12.4-18.3)$ & $4.1(2.7-12.4)$ & $3.7(2.5-5.3)$ & $0.9(0.4-1.3)$ & $29(37.7)$ & $33(42.9)$ & $45(58.4)$ & $14(19.2)$ \\
\hline Exon 19 deletion $(\mathrm{n}=13)$ & $12.3(10.6-16.6)$ & $5.2(3.2-23.4)$ & $2.5(1.8-3.9)$ & $0.6(0.5-0.8)$ & $4(30.8)$ & $7(53.8)$ & $6(46.2)$ & $0(0.0)$ \\
\hline L858R substitution $(\mathrm{n}=12)$ & $14.4(12.2-25.0)$ & $6.9(2.2-16.3)$ & $2.8(1.6-5.4)$ & $0.6(0.4-1.0)$ & $4(33.3)$ & $7(58.3)$ & $5(41.7)$ & $1(9.1)$ \\
\hline Others $(\mathrm{n}=4)$ & $14.6(10.5-20.0)$ & $5.9(3.6-8.3)$ & $3.6(2.8-4.2)$ & $1.8(0.4-2.3)$ & $1(25.0)$ & $3(75.0)$ & $2(50.0)$ & $1(25.0)$ \\
\hline$P$-value & 0.679 & 0.314 & 0.801 & 0.062 & 0.977 & 0.477 & 0.621 & 0.277 \\
\hline Total $(n=106)$ & $14.3(11.9-18.3)$ & $4.6(2.7-13.0)$ & $3.5(2.4-5.2)$ & $0.8(0.4-1.25)$ & $38(35.8)$ & $50(47.2)$ & $58(54.7)$ & $16(15.1)$ \\
\hline
\end{tabular}

carcinoma patients, respectively. Elevated preoperative NSE levels were closely associated with advanced clinical stage $(P=0.006)$, smoking history $(P=0.036)$ and regional lymph node metastasis $(P=0.005)$. In addition, median NSE levels in patients with larger tumor size were higher than those with smaller tumor size (14.7 versus 13.7 $\mathrm{ng} / \mathrm{ml}, P=0.045)$. And increased SCCA levels were found to be correlated with tumor size $(P=0.011)$. Neither CEA nor Cyfra21-1 levels were correlated with any clinical parameter in adenosquamous lung carcinoma patients. Median levels and positive rates for NSE, CEA, Cyfra21-1 or SCCA were similar regardless of EGFR mutation status in adenosquamous lung carcinoma patients. Similarly, no differences were found in positive rates and median levels of these tumor markers between del19 and L858R subtypes.

Moreover, as shown in Supplementary Table 1, EGFR mutations were found more frequently in women (48.8\% versus $\left.12.7 \%, \chi^{2}=16.795, P<0.001\right)$, neversmokers $\left(42.9 \%\right.$ versus $\left.17.2 \%, \chi^{2}=8.408, P=0.004\right)$ and younger patients $\left(36.0 \%\right.$ versus $19.6 \%, \chi^{2}=3.556, P=$ $0.059)$.

\section{Association of serum tumor markers, TMI and EGFR mutation status with DFS and OS}

Among the 106 adenosquamous lung carcinoma patients, 38 had elevated NSE levels, 50 elevated CEA, 58 elevated Cyfra21-1 and 16 elevated SCCA. DFS and OS were significantly shorter in patients with elevated NSE (9.6 versus 20.5 months, log-rank $\chi^{2}=9.638, P=$ 0.002 for DFS, Figure 1A; 16.0 versus 36.0 months, logrank $\chi^{2}=15.330, P<0.001$ for OS, Figure 1B). Patients with elevated Cyfra21-1 exhibited similar DFS (14.8 versus 15.0 months, log-rank $\chi^{2}=0.017, P=0.897$, Figure 1C) but shorter OS (22.0 versus 37.0 months, log-rank $\chi^{2}$ $=3.533, P=0.060$, Figure 1D). Neither CEA nor SCCA was correlated with any effect on DFS or OS (CEA: $P=$ 0.565 for DFS, Figure 1E; $P=0.604$ for OS, Figure 1F; SCCA: $P=0.796$ for DFS, Figure $1 \mathrm{G} ; P=0.940$ for OS, Figure $1 \mathrm{H})$.

The relationship between the TMI and survival in adenosquamous lung carcinoma patients is shown in Figure 2. There were 17 patients with TMI $\leq 0.54$ and 89 patients with TMI $>0.54$. The OS of patients with a TMI $\leq 0.54$ was longer than patients with a TMI $>0.54$ but no difference in DFS was found between the two groups (47.0 versus 14.0 months, log-rank $\chi^{2}=3.600, P=0.058$ for 


\begin{tabular}{|c|c|c|c|c|c|c|}
\hline \multirow[b]{2}{*}{ Variable } & \multicolumn{3}{|l|}{ DFS } & \multicolumn{3}{|l|}{ OS } \\
\hline & Median (months) & HR $(95 \% C I)$ & $P$-value & $\begin{array}{l}\text { Median } \\
\text { (months) }\end{array}$ & HR $(95 \% \mathrm{CI})$ & $P$-value \\
\hline \multicolumn{7}{|l|}{$\begin{array}{l}\text { Total }(\mathrm{n}=106) \\
\text { Age (years) }\end{array}$} \\
\hline$<60$ & 12.1 & Reference & 0.492 & 34.1 & Reference & 0.159 \\
\hline$\geq 60$ & 16.5 & $0.846(0.526-1.362)$ & & 22.0 & $1.411(0.874-2.280)$ & \\
\hline \multicolumn{7}{|l|}{ Gender } \\
\hline Male & 14.0 & Reference & 0.237 & 24.5 & Reference & 0.619 \\
\hline Female & 15.5 & $1.350(0.821-2.221)$ & & 29.0 & $1.132(0.695-1.844)$ & \\
\hline \multicolumn{7}{|l|}{ Smoking history } \\
\hline Never & 15.0 & Reference & 0.461 & 27.8 & Reference & 0.986 \\
\hline Ever & 15.0 & $1.206(0.733-1.986)$ & & 38.7 & $0.996(0.610-1.624)$ & \\
\hline \multicolumn{7}{|l|}{ Component } \\
\hline Adenocarcinoma predominant & 12.1 & Reference & 0.645 & 24.5 & Reference & 0.780 \\
\hline Squamous cell carcinoma predominant & 19.0 & $0.777(0.429-1.408)$ & & 34.0 & $0.910(0.507-1.635)$ & \\
\hline Equal proportion & 15.3 & $0.819(0.462-1.453)$ & & 33.8 & $0.816(0.463-1.440)$ & \\
\hline \multicolumn{7}{|l|}{ Clinical stage } \\
\hline $\mathrm{I}$ & 32.0 & Reference & 0.009 & 42.0 & Reference & 0.046 \\
\hline II & 15.5 & $1.447(0.706-2.966)$ & & 19.5 & $1.652(0.815-3.550)$ & \\
\hline IIIA & 9.6 & $2.335(1.345-4.052)$ & & 24.0 & $1.963(1.148-3.357)$ & \\
\hline \multicolumn{7}{|l|}{ Tumor size } \\
\hline$\leq 3 \mathrm{~cm}$ & 47.0 & Reference & 0.001 & 43.0 & Reference & 0.002 \\
\hline$>3 \mathrm{~cm}$ & 9.9 & $2.733(1.532-4.877)$ & & 20.5 & $2.434(1.403-4.225)$ & \\
\hline \multicolumn{7}{|l|}{ Regional lymph node metastasis } \\
\hline No & 32.0 & Reference & 0.024 & 37.0 & Reference & 0.030 \\
\hline Yes & 12.1 & $1.775(1.080-2.918)$ & & 22.0 & $1.720(1.055-2.804)$ & \\
\hline \multicolumn{7}{|l|}{ Operative approaches } \\
\hline Pneumonectomy & 12.5 & Reference & 0.203 & 16.0 & Reference & 0.167 \\
\hline Lobectomy & 15.5 & $0.511(0.242-1.078)$ & & 26.0 & $0.552(0.247-1.103)$ & \\
\hline Wedge resection & 10.0 & $0.631(0.218-1.802)$ & & 29.0 & $0.778(0.291-2.081)$ & \\
\hline \multicolumn{7}{|l|}{ Adjuvant treatment } \\
\hline Chemotherapy & 14.8 & Reference & 0.538 & 25.2 & Reference & 0.720 \\
\hline Chemoradiotherapy & 9.6 & $1.372(0.667-2.823)$ & & 25.5 & $0.782(0.333-1.836)$ & \\
\hline Others/none & 16.5 & $0.867(0.493-1.524)$ & & 36.0 & $0.830(0.484-1.423)$ & \\
\hline \multicolumn{7}{|l|}{ EGFR mutation } \\
\hline Wild-type & 15.3 & Reference & 0.893 & 33.8 & Reference & 0.642 \\
\hline Mutant & 14.0 & $0.963(0.560-1.656)$ & & 25.5 & $0.877(0.504-1.527)$ & \\
\hline \multicolumn{7}{|l|}{ NSE } \\
\hline$\leq 15.2 \mathrm{ng} / \mathrm{ml}$ & 20.5 & Reference & 0.002 & 36.0 & Reference & $<0.001$ \\
\hline$>15.2 \mathrm{ng} / \mathrm{ml}$ & 9.6 & $2.103(1.300-3.401)$ & & 16.0 & $2.504(1.555-4.031)$ & \\
\hline \multicolumn{7}{|l|}{ CEA } \\
\hline$\leq 5.0 \mathrm{ng} / \mathrm{ml}$ & 15.3 & Reference & 0.566 & 25.9 & Reference & 0.605 \\
\hline$>5.0 \mathrm{ng} / \mathrm{ml}$ & 14.8 & $1.150(0.713-1.856)$ & & 25.4 & $1.133(0.706-1.819)$ & \\
\hline \multicolumn{7}{|l|}{ Cyfra21-1 } \\
\hline$\leq 3.3 \mathrm{ng} / \mathrm{ml}$ & 15.0 & Reference & 0.897 & 37.0 & Reference & 0.063 \\
\hline$>3.3 \mathrm{ng} / \mathrm{ml}$ & 14.8 & $1.032(0.639-1.666)$ & & 22.0 & $1.593(0.975-2.601)$ & \\
\hline \multicolumn{7}{|l|}{ SCCA } \\
\hline$\leq 1.5 \mathrm{ng} / \mathrm{ml}$ & 15.0 & Reference & 0.723 & 27.0 & Reference & 0.986 \\
\hline$>1.5 \mathrm{ng} / \mathrm{ml}$ & 9.6 & $0.881(0.436-1.780)$ & & 14.5 & $0.994(0.491-2.011)$ & \\
\hline \multicolumn{7}{|l|}{ Tumor marker index (TMI) } \\
\hline$\leq 0.54$ & 47.0 & Reference & 0.063 & NR & Reference & 0.009 \\
\hline$>0.54$ & 14.0 & $2.020(0.961-4.246)$ & & 24.0 & $3.071(1.320-7.142)$ & \\
\hline $\begin{array}{l}\text { Clinical stage } I(n=41) \\
\text { NSE }\end{array}$ & & & & & & \\
\hline$\leq 15.2 \mathrm{ng} / \mathrm{ml}(\mathrm{n}=33)$ & 32.0 & Reference & 0.147 & 42.0 & Reference & 0.132 \\
\hline$>15.2 \mathrm{ng} / \mathrm{ml}(\mathrm{n}=8)$ & 9.0 & $2.017(0.781-5.209)$ & & 15.2 & $2.027(0.809-5.081)$ & \\
\hline TMI & & & & & & \\
\hline
\end{tabular}




\begin{tabular}{|l|l|l|l|l|l|l|l|}
\hline$\leq 0.54(\mathrm{n}=11)$ & NR & Reference & 0.213 & NR & Reference & 0.113 \\
\hline$>0.54(\mathrm{n}=30)$ & 15.0 & $1.998(0.671-5.949)$ & & 36.0 & $2.399(0.812-7.090)$ & \\
\hline $\begin{array}{l}\text { Clinical stage II-IIIA }(\mathrm{n}=65) \\
\text { NSE }\end{array}$ & 15.3 & Reference & 0.028 & 34.0 & Reference & 0.005 \\
\hline$\leq 15.2 \mathrm{ng} / \mathrm{ml}(\mathrm{n}=35)$ & 9.6 & $1.926(1.075-3.453)$ & & 15.5 & $2.345(1.296-4.243)$ & \\
\hline$>15.2 \mathrm{ng} / \mathrm{ml}(\mathrm{n}=30)$ & 7.6 & Reference & 0.360 & NR & Reference & 0.092 \\
\hline TMI & 12.5 & $1.632(0.571-4.663)$ & & 20.7 & $3.409(0.817-14.217)$ & \\
\hline$\leq 0.54(\mathrm{n}=6)$ &
\end{tabular}

\begin{tabular}{|l|l|l|l|l|l|l|}
\hline Table 4: Multivariate analysis of DES and OS & & & OS & \\
\hline & & DFS & & & 95\%CI & $\boldsymbol{P}$-value \\
\hline Variable & HR & $\mathbf{9 5 \% C I}$ & $\boldsymbol{P}$-value & HR & $\mathbf{9 5}$ & \\
\hline Clinical stage (I vs. II-IIIA) & 1.589 & $0.922-2.738$ & 0.096 & & & 0.001 \\
\hline NSE $(>15.2 \mathrm{ng} / \mathrm{ml}$ vs. $\leq 15.2 \mathrm{ng} / \mathrm{ml})$ & 1.862 & $1.131-3.066$ & 0.014 & 2.199 & $1.355-3.568$ & 0.038 \\
\hline $\begin{array}{l}\text { Tumor marker index (TMI) }(>0.54 \text { vs. } \leq \\
0.54)\end{array}$ & & & & 2.479 & $1.050-5.855$ & \\
\hline
\end{tabular}

DFS, Figure 2A; Not Reached [NR] versus 24.0 months, $\log$-rank $\chi^{2}=7.534, P=0.006$ for OS, Figure 2B).

Moreover, in those patients with stage II and IIIA diseases, elevated NSE levels were associated with shorter DFS and OS (9.6 versus 15.3 months, log-rank $\chi^{2}=5.036$, $P=0.025$ for DFS, Figure 2C; 15.5 versus 34.0 months, log-rank $\chi^{2}=8.479, P=0.004$ for OS, Figure 2D), while this relationship between increased NSE and DFS or OS was not found in stage I patients.

As shown in Table 3, similar DFS and OS were observed in patients regardless of EGFR mutation status ( $P=0.893$ for DFS; $P=0.642$ for OS). Of the 29 adenosquamous lung carcinoma patients with EGFR mutations, no difference was found in DFS and OS between del19 and L858R subgroups ( $P=0.595$ for DFS; $P=0.778$ for OS).

\section{Univariate and multivariate analysis of prognostic factors}

By univariate analysis, advanced clinical stage $(P$ $=0.009$ for DFS; $P=0.046$ for OS), larger tumor size $(P=0.001$ for DFS; $P=0.002$ for OS $)$, regional lymph node metastasis $(P=0.024$ for DFS; $P=0.030$ for OS $)$, higher NSE level ( $P=0.002$ for DFS; $P<0.001$ for OS), and higher TMI $(P=0.009$ for OS) were significantly correlated with a worse prognosis (Table 3 ).

By multivariate analysis, elevated NSE (hazard ratio $[\mathrm{HR}]=1.862 ; 95 \% \mathrm{CI}$ : $1.131-3.066 ; P=0.014)$ was confirmed as independent predictors for DFS, while increased NSE (HR $=2.199 ; 95 \% \mathrm{CI}: 1.355-3.568 ; P=$ $0.001)$ and TMI (HR $=2.479 ; 95 \%$ CI: $1.050-5.855, P=$ 0.038 ) were independent prognostic factors for OS (Table $4)$.

\section{DISCUSSION}

Preoperative serum tumor markers secreted by tumor cells might reflect intratumor heterogeneity, and have been investigated as tools for predicting disease progression, either alone, or in combination with clinical variables [14]. However, the predictive and prognostic significance of the tumor markers for adenosquamous lung carcinoma remains largely unknown. EGFR mutations are most common in adenocarcinoma, while their frequency in the context of adenosquamous lung carcinoma remains controversial.

In this study, we found that the EGFR mutation rate $(29 / 106,27.4 \%)$ was relatively high in adenosquamous lung carcinoma patients but had no effect on disease-free survival or overall survival. Furthermore, we demonstrated that elevated NSE and TMI were independently unfavorable predictors. No significant difference in disease-free survival or overall survival were observed between patients with high carcinoembryonic antigen (CEA), cytokeratin 19 fragments (Cyfra21-1) or squamous cell carcinoma antigen (SCCA) levels compared to those with lower levels.

Several studies have demonstrated that the survival rate of adenosquamous lung carcinoma patients is shorter than other types of non-small cell lung cancer. The reported 5-year survival rate for adenosquamous lung carcinoma patients has varied between $6.2 \%$ and $25.4 \%[1,15-18]$. In the present study, we observed that the 5 -year survival rate to be approximately $25.3 \%$. In addition, the high frequency of lymph nodal metastases $(59 / 106,55.7 \%)$ and advanced pathological stage (46/106, $43.4 \%$ ) at surgery underscores the aggressive behavior of adenosquamous lung carcinoma. Moreover, more than half adenosquamous lung carcinoma patients who underwent complete surgical resection experienced distant metastases or local recurrences $(68 / 106,64.2 \%)$ including distant brain metastases $(11 / 68)$, consistent with the results of a prior study [1].

A previous study found that the amount of adenocarcinoma components did not affect the survival rate, while another reported that adenocarcinoma predominant tumors were considered to be a worse prognostic factor [18-20]. Conversely, Gawrychowski et al 
observed that a balance of squamous and adenocarcinoma components had better prognosis than either being predominant [17]. In the present study we found no significant difference in disease-free survival or overall survival between adenosquamous lung carcinoma patients based on dominant component. This difference in results between our study and others could be attributed to different sample sizes, or the fact that biopsies come from small regions of the tumor which may underrepresent adenosquamous carcinoma histologic characteristics.

EGFR mutation has been reported to be a good outcome predictor for patients with non-small cell lung cancer. Consistent with previous studies [21, 22], we observed that EGFR mutation frequency was increased in never-smokers and in females. However, no correlation between EGFR mutation status and patient survival was observed, which may result from the low incidence of EGFR-TKI treatment in this cohort (5/29). Two additional

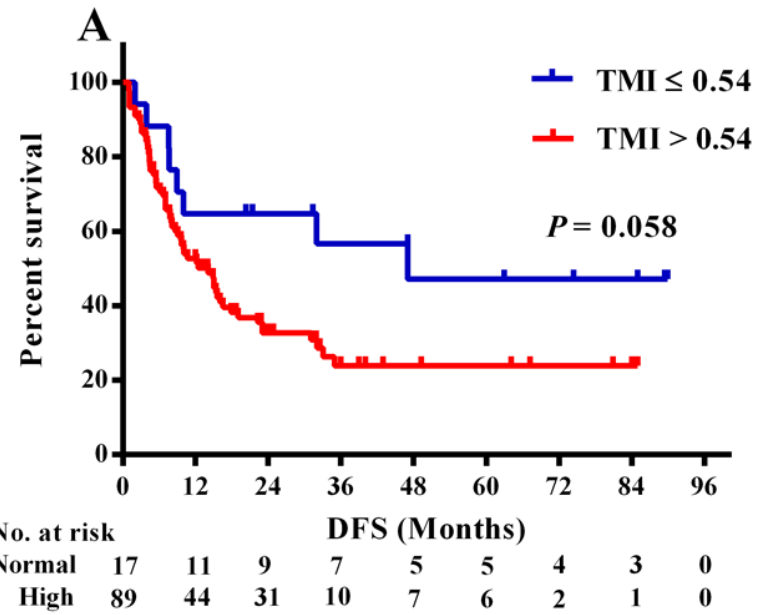

Clinical stage II-IIIA

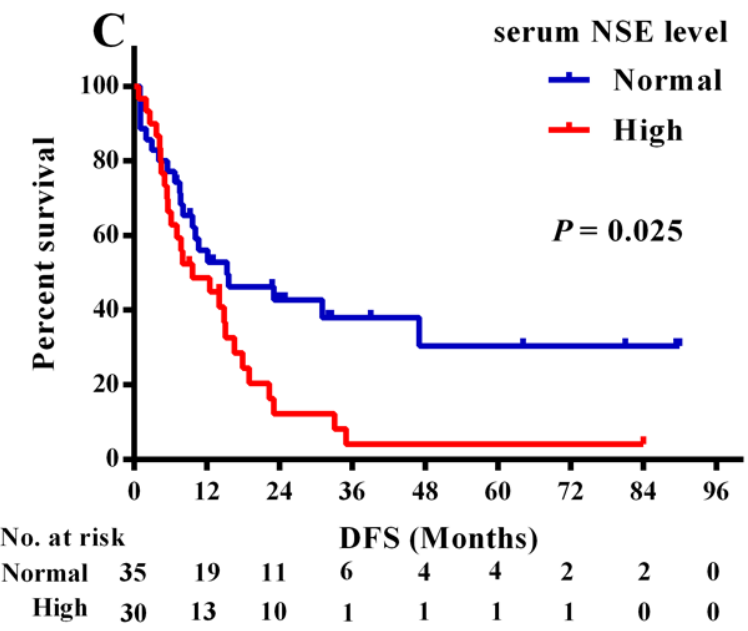

reports were unable to detect a significant association between EGFR mutation and prognosis in patients who did not receive EGFR-TKI therapy [23, 24]. In addition, a prior study showed an adenosquamous lung carcinoma patient harboring EGFR-sensitizing mutation had a remarkable response to gefitinib [25]. Therefore EGFR tyrosine kinase inhibitors would be a reasonable therapeutic option to adenosquamous lung carcinoma patients due to the relatively high frequency of EGFR mutations in this cohort.

According to previous studies, serum NSE level in non-small cell lung cancer may reflect the heterogeneity and neuroendocrine phenotype and was as a prognostic factor for neuroendocrine lung tumors [26, 27]. However, the predictive value of NSE in non-small cell lung cancer are unclear, since several studies did not observe a prognostic role, while others have reported that elevated NSE is associated with poor prognosis $[7,8,28]$. NSCLC

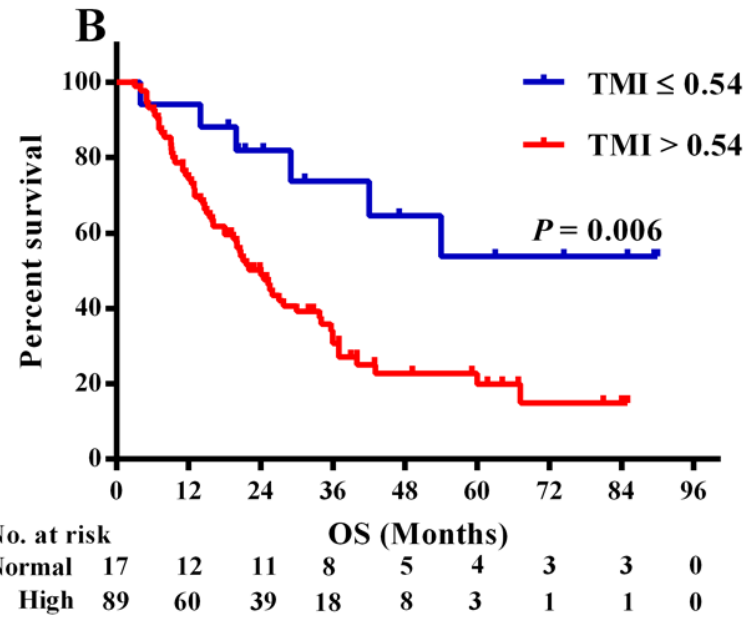

Clinical stage II-IIIA

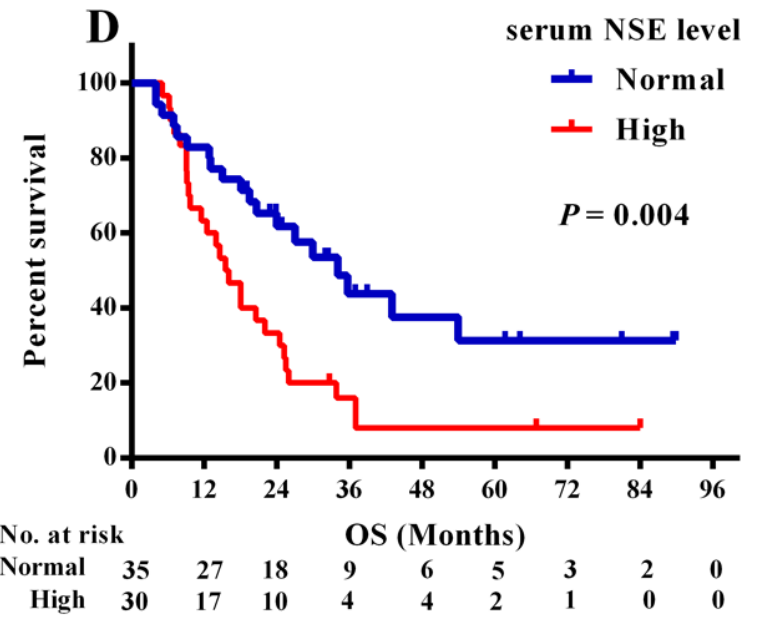

Figure 2: Kaplan-Meier survival curves of DFS and OS based on TMI as well as NSE levels. A. DFS and B. OS based on different levels of TMI. C. DFS and D. OS based on different NSE levels in stage II-IIIA patients $(n=65)$. 
with neuroendocrine properties was previously reported to be chemosensitive but was associated with poorer outcomes similar to small cell lung cancer.[29] In another study, elevated serum NSE predicted NSCLC resistance to EGFR-TKIs and it was speculated that transition to small cell lung cancer occurred after acquisition of EGFR-TKI resistance [9]. Interestingly, sequential NSE level measurement has predicted tumor recurrence, dropping during effective treatment, but rising again after relapse [30, 31]. And Bastide et al. found adenosquamous lung carcinoma is more phenotypically similar to neuroendocrine tumors compared to adenocarcinoma lung cancer or squamous cell lung cancer [32]. Further, we confirmed that high NSE level in adenosquamous lung carcinoma confers a poorer prognosis. A strong positive association was identified between preoperative NSE and clinical stage as well as lymph node metastasis. Elevated NSE levels gave a poorer prognosis to patients with advanced staged tumors compared to those with earlier stage disease. These results suggest that NSE reflects tumor burden and aggressiveness, consistent with previous studies. Therefore, our results suggest that these patients should undertake a more aggressive clinical course.

Cyfra21-1 and CEA have been confirmed as valuable prognostic factors for NSCLC. Previous studies found that Cyfra21-1 tends to be more useful for squamous cell carcinoma diagnosis while CEA is predictive for adenocarcinoma.[10, 12, 33] In our study, elevated levels of neither Cyfra21-1 nor CEA were associated adenosquamous lung carcinoma patient prognosis. Interestingly, the TMI evaluating both Cyfra21-1 and CEA simultaneously was an independent prognostic marker for overall survival $(\mathrm{HR}=2.479$, 95\% CI: $1.050-5.855, P=0.038$ ). This result might reflect that adenosquamous lung carcinoma stems from a monoclonal expansion of a single mutant progenitor cell clone, maintaining both adenocarcinoma and squamous cell carcinoma characteristics [32, 34, 35]. However, the molecular mechanism of trans-differentiation into adenocarcinoma or squamous cell carcinoma requires furthermore exploration.

Our retrospective study has some limitations. First, some data was censored, the patient sample size was relatively small, and patients undertook different chemotherapeutic regimens. In addition, we did not investigate the adenosquamous lung carcinoma components separately so it is not known which harbored identified EGFR mutations. It has been reported that adenocarcinoma and squamous cell carcinoma components can possess the same EGFR mutation, suggesting that the histologic origin of adenosquamous lung carcinoma can be monoclonal [22].

In conclusion, our results demonstrate that elevated preoperative NSE level has adverse predictive and prognostic value. In addition, TMI based on serum CEA and Cyfra21-1 is also an independent prognostic for overall survival. A larger prospective study will be needed to confirm these results.

\section{PATIENTS AND METHODS}

\section{Patients}

A total of 106 adenosquamous lung carcinoma patients who underwent curative-intent complete resection between January 2008 and January 2013 at the Tianjin Medical University Cancer Institute \& Hospital were enrolled in this retrospective study. The study was approved by the Institutional Review Board of Tianjin Medical University Cancer Institute \& Hospital and informed consent was obtained from all patients. The following patients are excluded: (1) locally advanced (stage IIIB), metastasized (stage IV), or postsurgically relapsed adenosquamous lung carcinoma; (2) insufficient tissue specimens or unavailable for genetic analysis; (3) blood samples not obtained before operation, or serum tumor marker records were unavailable; (4) patients who died within one month after surgery; (5) preoperative chemotherapy or radiotherapy; and (6) history of second primary cancer diagnosed within 5 years. Patient characteristics are shown in Table 1.

In terms of World Health Organization histological classification ( $3 \mathrm{rd}$ edition), if the percentage of one of the tumor components was less than $10 \%$, such cancer was defined according to predominating texture and added 'with elements' [3]. Such patients were not taken into account in this study. If each of the components account for $40-60 \%$, such cases were regarded as balanced and classified according to adenocarcinoma and squamous cell carcinoma characteristics shown in each case into the following subgroups: Adenocarcinoma predominant group, in which the adenocarcinoma component was equal to or more than $60 \%$ of tumor cells; Squamous cell carcinoma predominant group, in which the adenocarcinoma component was less than 50\%; and equal adenocarcinoma and squamous cell carcinoma group, in which the adenocarcinoma component was 50\%-60\%.

\section{Measurement of serum NSE, CEA, Cyfra21-1 and SCCA levels and EGFR mutations}

Serum concentrations of NSE, CEA, Cyfra21-1 and SCCA were measured within 2 weeks before surgery by electrochemiluminescence immunoassay on Roche Analytics E170 Immunology Analyzer (Roche Diagnostics, China). Based on the manufacturer's recommendation, the following cut-offs for serum marker levels were used: NSE $15.2 \mathrm{ng} / \mathrm{ml}$, CEA $5.0 \mathrm{ng} / \mathrm{ml}$, Cyfra21-1 $3.3 \mathrm{ng} / \mathrm{ml}$ and SCCA $1.5 \mathrm{ng} / \mathrm{ml}$.

Tumor marker index (TMI) was defined by the 
geometric mean of normalized CEA and Cyfra21-1. It was calculated as described recently $(\mathrm{TMI}=$ square root of CEA concentration $/ 5.0 \mathrm{ng} / \mathrm{ml} \times$ Cyfra21-1 concentration $/ 3.3 \mathrm{ng} / \mathrm{ml}$ ). The cut-off point for TMI was 0.54 according to results of Muley et al [36].

EGFR mutations were identified by polymerase chain reaction based direct sequencing to detect the nucleotide sequencing of the kinase domain of EGFR of individual exons (18-21 exons).

\section{Statistical analysis}

Data are presented as the mean $\pm \mathrm{SD}$ or median and IQR (intraquartile range). Fisher's exact test or chisquare test was conducted to compare the distribution of categorical variables. The Mann-Whitney U-test or Kruskal-Wallis one-way ANOVA test was used to compare continuous data. Overall survival (OS) was defined as the time from the date of surgery to the date of final follow-up or death from any cause. Disease-free survival (DFS) was calculated from the date of surgery until the date of the first recurrence or death from any cause. The survival curves were estimated using the Kaplan-Meier method, and differences were evaluated using the log-rank test. Hazard ratios (HR) and 95\% confidence intervals $(95 \% \mathrm{CI})$ were assessed by univariate and multivariate analyses using the Cox proportional hazards model. The independent prognostic factor was estimated by the Cox proportional hazards model using stepwise regression (backward selection). A $P$ value less than 0.05 was considered to indicate a statistically significant difference. SPSS 22.0 for Windows (SPSS, Chicago IL) was performed to analyze data.

\section{ACKNOWLEDGMENTS AND FUNDING}

We are grateful to Dr. Douglas E. Linn (Brigham \& Women's Hospital, Boston, MA, USA) for critical reading of the manuscript.

This work was supported by grants from the National Natural Science Foundation of China (No. 81372517 and No. 81000899 for Richeng Jiang), the Tianjin Municipal Science and Technology Commission Key Application Research Projects (No. 11JCZDJC18900) for Richeng Jiang, the National Natural Science Foundation of China (No. 81501983) for Dongsheng Yue, National Science and Technology Major Project (No. 2013ZX) for Yi Ba, and the Tianjin Municipal Science and Technology Commission Projects (No. 11JCYBJC11300 and No. 12ZCDZSY15600) for Kai Li.

\section{CONFLICTS OF INTEREST}

The authors have declared no conflicts of interest.

\section{REFERENCES}

1. Filosso PL, Ruffini E, Asioli S, Giobbe R, Macri L, Bruna MC, Sandri A, and Oliaro A. Adenosquamous lung carcinomas: a histologic subtype with poor prognosis. Lung Cancer. 2011; 74: 25-29.

2. Jemal A, Thun MJ, Ries LA, Howe HL, Weir HK, Center MM, Ward E, Wu XC, Eheman C, Anderson R, Ajani UA, Kohler B, and Edwards BK. Annual report to the nation on the status of cancer, 1975-2005, featuring trends in lung cancer, tobacco use, and tobacco control. J Natl Cancer Inst. 2008; 100: 1672-1694.

3. Travis W, Colby T, Corrin B, and al e. In Collaboration with L.H. Sobin and Pathologists from 14 Countries. Histological Typing of Lung and Pleural Tumours (International Histological Classification of Tumours). Geneva: World Health Organization. 1999; 1-55.

4. Maeda H, Matsumura A, Kawabata T, Suito T, Kawashima O, Watanabe T, Okabayashi K, Kubota I, and Japan National Hospital Organization Study Group for Lung C. Adenosquamous carcinoma of the lung: surgical results as compared with squamous cell and adenocarcinoma cases. Eur J Cardiothorac Surg. 2012; 41: 357-361.

5. Mok TS, Wu YL, Thongprasert S, Yang CH, Chu DT, Saijo N, Sunpaweravong P, Han B, Margono B, Ichinose Y, Nishiwaki Y, Ohe Y, Yang JJ, et al. Gefitinib or carboplatin-paclitaxel in pulmonary adenocarcinoma. N Engl J Med. 2009; 361: 947-957.

6. Tanaka K, Hata A, Kaji R, Fujita S, Otoshi T, Fujimoto D, Kawamura T, Tamai K, Takeshita J, Matsumoto T, Monden K, Nagata K, Otsuka K, et al. Cytokeratin 19 fragment predicts the efficacy of epidermal growth factor receptor-tyrosine kinase inhibitor in non-small-cell lung cancer harboring EGFR mutation. J Thorac Oncol. 2013; 8: 892-898.

7. Ferrigno D, Buccheri G, and Giordano C. Neuron-specific enolase is an effective tumour marker in non-small cell lung cancer (NSCLC). Lung Cancer. 2003; 41: 311-320.

8. Yan HJ, Tan Y, and Gu W. Neuron specific enolase and prognosis of non-small cell lung cancer: a systematic review and meta-analysis. J buon. 2014; 19: 153-156.

9. Inomata M, Hayashi R, Yamamoto A, Tokui K, Taka C, Okazawa S, Kambara K, Suzuki K, Ichikawa T, Yamada T, Miwa T, Kashii T, Matsui S, et al. Plasma neuron-specific enolase level as a prognostic marker in patients with nonsmall cell lung cancer receiving gefitinib. Mol Clin Oncol. 2015; 3: 802-806.

10. Grunnet $\mathrm{M}$ and Sorensen JB. Carcinoembryonic antigen (CEA) as tumor marker in lung cancer. Lung Cancer. 2012; 76: $138-143$.

11. Wang XB, Li J, and Han Y. Prognostic significance of preoperative serum carcinoembryonic antigen in non-small cell lung cancer: a meta-analysis. Tumour Biol. 2014; 35 : 10105-10110. 
12. Pujol JL, Molinier O, Ebert W, Daures JP, Barlesi F, Buccheri G, Paesmans M, Quoix E, Moro-Sibilot D, Szturmowicz M, Brechot JM, Muley T, and Grenier J. CYFRA 21-1 is a prognostic determinant in non-small-cell lung cancer: results of a meta-analysis in 2063 patients. $\mathrm{Br}$ J Cancer. 2004; 90: 2097-2105.

13. Vassilakopoulos T, Troupis T, Sotiropoulou C, Zacharatos P, Katsaounou P, Parthenis D, Noussia O, Troupis G, Papiris S, Kittas C, Roussos C, Zakynthinos S, and Gorgoulis V. Diagnostic and prognostic significance of squamous cell carcinoma antigen in non-small cell lung cancer. Lung Cancer. 2001; 32: 137-144.

14. Jiang R, Wang X, and Li K. Predictive and prognostic value of preoperative serum tumor markers is EGFR mutation-specific in resectable non-small-cell lung cancer. Oncotarget. 2016; 7: 26823-26836. doi: 10.18632/ oncotarget.8662.

15. Nakagawa K, Yasumitu T, Fukuhara K, Shiono H, and Kikui M. Poor prognosis after lung resection for patients with adenosquamous carcinoma of the lung. Ann Thorac Surg. 2003; 75: 1740-1744.

16. Maeda $H$, Matsumura A, Kawabata $T$, Suito $T$, Kawashima O, Watanabe T, Okabayashi K, and Kubota I. Adenosquamous carcinoma of the lung: surgical results as compared with squamous cell and adenocarcinoma cases. Eur J Cardiothorac Surg. 2012; 41: 357-361.

17. Gawrychowski J, Brulinski K, Malinowski E, and Papla B. Prognosis and survival after radical resection of primary adenosquamous lung carcinoma. European Journal of Cardio-Thoracic Surgery. 2005; 27: 686-692.

18. Shimizu J, Oda M, Hayashi Y, Nonomura A, and Watanabe Y. A clinicopathologic study of resected cases of adenosquamous carcinoma of the lung. Chest. 1996; 109: 989-994.

19. Takamori S, Noguchi M, Morinaga S, Goya T, Tsugane $\mathrm{S}$, Kakegawa T, and Shimosato Y. Clinicopathologic characteristics of adenosquamous carcinoma of the lung. Cancer. 1991; 67: 649-654.

20. Guo Y, Jia L, Shao GG, Sun HW, Wang XX, Wang GJ, and $\mathrm{Ma} \mathrm{KW}$. Clinicopathological characteristics and prognosis of patients with adenosquamous lung carcinoma. J Huazhong Univ Sci Technolog Med Sci. 2015; 35: 350355 .

21. Morodomi Y, Okamoto T, Takenoyama M, Takada K, Katsura M, Suzuki Y, Fujishita T, Kitahara H, Shimamatsu S, Kohno M, Tagawa T, Okano S, Taguchi K, et al. Clinical Significance of Detecting Somatic Gene Mutations in Surgically Resected Adenosquamous Cell Carcinoma of the Lung in Japanese Patients. Ann Surg Oncol. 2015; 22: 2593-2598.

22. Kang SM, Kang HJ, Shin JH, Kim H, Shin DH, Kim SK, Kim JH, Chung KY, Kim SK, and Chang J. Identical epidermal growth factor receptor mutations in adenocarcinomatous and squamous cell carcinomatous components of adenosquamous carcinoma of the lung.
Cancer. 2007; 109: 581-587.

23. Shigematsu H, Lin L, Takahashi T, Nomura M, Suzuki M, Wistuba, II, Fong KM, Lee H, Toyooka S, Shimizu N, Fujisawa T, Feng Z, Roth JA, et al. Clinical and biological features associated with epidermal growth factor receptor gene mutations in lung cancers. J Natl Cancer Inst. 2005; 97: 339-346.

24. Na, II, Rho JK, Choi YJ, Kim CH, Koh JS, Ryoo BY, Yang $\mathrm{SH}$, and Lee JC. Clinical features reflect exon sites of EGFR mutations in patients with resected non-small-cell lung cancer. J Korean Med Sci. 2007; 22: 393-399.

25. Iwanaga K, Sueoka-Aragane N, Nakamura T, Mori D, and Kimura S. The long-term survival of a patient with adenosquamous lung carcinoma harboring EGFR-activating mutations who was treated with gefitinib. Intern Med. 2012; 51: 2771-2774.

26. Bajetta E, Ferrari L, Martinetti A, Celio L, Procopio G, Artale S, Zilembo N, Di Bartolomeo M, Seregni E, and Bombardieri E. Chromogranin A, neuron specific enolase, carcinoembryonic antigen, and hydroxyindole acetic acid evaluation in patients with neuroendocrine tumors. Cancer. 1999; 86: 858-865.

27. Baudin E, Gigliotti A, Ducreux M, Ropers J, Comoy E, Sabourin JC, Bidart JM, Cailleux AF, Bonacci R, Ruffie $\mathrm{P}$, and Schlumberger M. Neuron-specific enolase and chromogranin A as markers of neuroendocrine tumours. Br J Cancer. 1998; 78: 1102-1107.

28. Andoh M, Gemma A, Takenaka K, Hisakatsu S, Yamada K, Usuki J, Hasegawa K, Sakonji M, Kudoh S, Tsuboi E, and et al. Serum neuron specific enolase level as a prognostic factor in non-small cell lung cancer. Intern Med. 1994; 33 : 271-276.

29. Gazdar AF, Kadoyama C, Venzon D, Park JG, Tsai CM, Linnoila RI, Mulshine JL, Ihde DC, and Giaccone G. Association between histological type and neuroendocrine differentiation on drug sensitivity of lung cancer cell lines. J Natl Cancer Inst Monogr. 1992; 191-196.

30. Cooper EH, Splinter TA, Brown DA, Muers MF, Peake $\mathrm{MD}$, and Pearson SL. Evaluation of a radioimmunoassay for neuron specific enolase in small cell lung cancer. Br J Cancer. 1985; 52: 333-338.

31. Johnson DH, Marangos PJ, Forbes JT, Hainsworth JD, Van Welch R, Hande KR, and Greco FA. Potential utility of serum neuron-specific enolase levels in small cell carcinoma of the lung. Cancer Res. 1984; 44: 5409-5414.

32. Bastide $\mathrm{K}$, Ugolin $\mathrm{N}$, Levalois $\mathrm{C}$, Bernaudin J-F, and Chevillard S. Are adenosquamous lung carcinomas a simple mix of adenocarcinomas and squamous cell carcinomas, or more complex at the molecular level? Lung Cancer. 2010; 68: $1-9$.

33. Blankenburg F, Hatz R, Nagel D, Ankerst D, Reinmiedl J, Gruber C, Seidel D, and Stieber P. Preoperative CYFRA 21-1 and CEA as Prognostic Factors in Patients with Stage I Non-Small Cell Lung Cancer. Tumor Biology. 2008; 29: 272-277. 
34. Kanazawa H, Ebina M, Ino-oka N, Shimizukawa M, Takahashi T, Fujimura S, Imai T, and Nukiwa T. Transition from squamous cell carcinoma to adenocarcinoma in adenosquamous carcinoma of the lung. American Journal of Pathology. 2000; 156: 1289-1298.

35. Vassella E, Langsch S, Dettmer MS, Schlup C, Neuenschwander M, Frattini M, Gugger M, and Schafer SC. Molecular profiling of lung adenosquamous carcinoma: hybrid or genuine type? Oncotarget. 2015; 6: 23905-23916. doi: 10.18632/oncotarget.4163.
36. Muley T, Fetz TH, Dienemann H, Hoffmann H, Herth FJ, Meister M, and Ebert W. Tumor volume and tumor marker index based on CYFRA 21-1 and CEA are strong prognostic factors in operated early stage NSCLC. Lung Cancer. 2008; 60: 408-415. 